\title{
PROTOTYPE SELF EMULSIFYING SYSTEM OF ETRAVIRINE: DESIGN, FORMULATION AND IN VITRO EVALUATION
}

\author{
G. B. PREETHI ${ }^{*}$, H. N. SHIVAKUMAR ${ }^{2}$, M. RAVI KUMAR ${ }^{4}$, N. SWETA ${ }^{4}$
}

\author{
${ }^{1,2,4}$ Department of Pharmaceutics, KLEU College of Pharmacy, Bengaluru, ${ }^{3}$ Geethanjali College of Pharmacy, Cheeryal (V), Keesara (M), RR \\ District, Telangana \\ Email: preethigb.mmm@gmail.com \\ Received: 21 Sep 2017, Revised and Accepted: 09 Jan 2018
}

\section{ABSTRACT}

Objective: Lipid-based formulations have gained much attention, particularly on self-emulsifying drug delivery systems (SEDDS), to improve the oral bioavailability of lipophilic drugs. In the present study, an attempt was made to develop and evaluate prototype SEDDS of poorly soluble antiviral BCS class IV drug etravirine.

Methods: Various oils, surfactants and co-surfactants were screened for their suitability in the formulation of SEDDS. Based on the screening, gelucire 44/14, as the oil, labrasol as a surfactant and transcutol HP as the co-surfactant were selected. SEDDS with drug etravirine was formulated and evaluated for emulsifying ability, dilution potential and microscopic properties. The emulsion area for each of the combination of oil and surfactant co-surfactant mixture $\left(\mathrm{S}_{\mathrm{mix}}\right)$ was determined by the construction of pseudo-ternary phase diagrams.

Results: The optimized formulation with oil (gelucire 44/14) and $\mathrm{S}_{\text {mix }}$ (labrasol: transcutol HP, 6:1) in a ratio of 2:8 exhibited a rapid emulsification rate and a good polydispersibility index of $0.103 \pm 0.012$ indicating uniformity of the formed droplets. The size of the droplets was determined by zetasizer and was found to be in $200 \mathrm{~nm}$ range. The drug release from the final formulation after $2 \mathrm{hr}$ was found to be $41.15 \% \pm 0.5$ compared to $19.3 \% \pm 3.8$ of pure drug indicating enhanced dissolution profile of the drug.

Conclusion: In vitro study illustrated enhanced dissolution rate of formulated prototype SEDDS of BCS class IV drug etravirine for oral delivery.

Keywords: Etravirine, SEDDS, Gelucire 44/1, BCS class IV, Labrasol, Transcutol

(C) 2018 The Authors. Published by Innovare Academic Sciences Pvt Ltd. This is an open access article under the CC BY license (http://creativecommons.org/licenses/by/4.0/) DOI: http://dx.doi.org/10.22159/ijap.2018v10i2.22714

\section{INTRODUCTION}

Though management of HIV infection has been done successfully with antiviral drug therapy it is coupled with several limitations and inconveniences. The reason being most of the anti-retroviral drugs display poor oral bioavailability and a short half-life owing to poor aqueous solubility, extensive first-pass effect and gastrointestinal degradation. This invariably results in localized HIV in the certain inaccessible region of the body such as the CNS, the lymphatic system and macrophages [1,2].

FDA has approved etravirine a second generation Non-nucleoside reverse transcriptase inhibitors (NNRTI) for the treatment of HIV-1 infection as it displays sustained virologic efficacy in a patient with NNRTI resistant HIV-1 infection. The drug undergoes extensive firstpass metabolism as it is metabolized by hepatic cytochrome $\mathrm{P} 450$ (CYP) 3A4 and other members of the CYP2C family. Etravirine is categorized under BCS class IV drug by virtue of its low aqueous solubility and permeability. It is highly lipophilic drug with $\log \mathrm{P}$ value greater than 5 as it is nearly insoluble in water over a wide range of physiological $\mathrm{pH}$ [3-7].

BCS class IV drugs are challenging molecule in product development as they exhibit low solubility and low permeability. However, formulation approaches similar to those for BCS class II drugs could be practically applied to BCS class IV drugs. Various approaches to overcome the poor aqueous solubility of drug candidates have been investigated and reported in the literature. In recent years, Lipidbased formulations have been utilized to enhance the oral bioavailability of BCS class IV drugs and Self emulsifying drug delivery systems (SEDDS) is one among them [8-12].

SEDDS are an isotropic mixture of oils, surfactants and cosurfactants, which forms fine o/w emulsion upon dilution with the aqueous gastrointestinal medium on gentle agitation [13-16]. For lipophilic drug compounds exhibiting dissolution rate limited absorption, these systems offer an advantage to deliver lipophilic drugs to the systemic circulation, by avoiding the dissolution step
(25). SEDDS improve the mucus permeation, rate and extent of absorption by facilitated intestinal lymphatic transport of drugs, as they are known to protect against enzymatic hydrolysis and inhibit P-gp efflux [17-19]. Some of the commercially successful antiviral SEDDS formulations are norvir (ritonavir) and Fortovase (saquinavir) generates (amprenavir), sustivas (efavirenz), and kaletras (lopinavir and ritonavir) [8].

Based on extensive review of literature it is understood that there is not much work done on SEDDS of etravirine. Thus the current study was aimed to develop prototype SEDDS of etravirine and evaluate the emulsifying ability, microscopic property, stability and it's in vitro dissolution.

\section{MATERIALS AND METHODS}

\section{Material}

Etravirine was obtained as a generous gift sample from Apotex Pharmachem INC (Bengaluru, India). Labrafil 2125 CS, peceol, gelucire 44/14, labrafac, lipophile WL 1349, lauroglycol-90, maisine35, labrasol and transcutol-HP are gift samples obtained from Gattefosse India (Mumbai, India). Captex 300 and captex 355 are gifted samples from Abitec Corporation (India). Tween 20, tween 60, span 20, span 80, PEG 200, PEG 400 were purchased from SD fine chemicals (Mumbai, India). Tri-Ester F-810 generous gift from India commercial company Private Ltd. Capmul MCM C8 L2p and captex 200 P are gifted samples from IMCD India private limited (Mumbai, India). All other chemicals and reagents were of analytical grade and procured from Merck (Mumbai, India) and SD Fine Chem. (Mumbai, India).

\section{Determination of solubility of etravirine in various vehicles}

The solubility of etravirine was determined in various oils, surfactants and co-surfactants by adding an excess amount of Etravirine in $1 \mathrm{ml}$ of a pure vehicle taken in glass tubes and the mixture was heated at $60{ }^{\circ} \mathrm{C}$ in a water bath and vortexed intermittently to facilitate the solubilization. The drug suspension was equilibrated at $25^{\circ} \mathrm{C}$ in a thermostatically controlled bath for 48 
h. After equilibration, the tubes were centrifuged at 12,000 RPM for $20 \mathrm{~min}$ and aliquots of the clear supernatants were further diluted with methanol or DMSO (based on the miscibility of the vehicle) and estimated for Etravirine by UV spectrophotometer at $317 \mathrm{~nm}$ for DMSO and $315 \mathrm{~nm}$ for methanol.

\section{Selection of surfactant}

The surfactants were screened based on their ability to emulsify the selected oil phase. To determine the emulsification ability, $20 \mu \mathrm{l}$ of surfactant was mixed with $20 \mu \mathrm{l}$ of the selected oily phase. Subsequently, $25 \mu \mathrm{l}$ of this mixture was diluted to $25 \mathrm{ml}$ with distilled water. The number of inversions of volumetric flask required to produce a uniform emulsion was monitored. The emulsions were allowed to stand for $2 \mathrm{~h}$ and their transmittance was measured at $638.2 \mathrm{~nm}$ in UV-vis spectrophotometer against distilled water as the blank [20,24].

\section{Selection of co-surfactant}

Co-surfactants were screened based on their efficacy to improve the emulsification ability of the selected surfactants. For this, $40 \mu \mathrm{l}$ of selected surfactant was mixed with $20 \mu \mathrm{l}$ of the co-surfactant $\left(\mathrm{S}_{\text {mix }}\right.$ ratio of 2:1). The selected oil was added to surfactant and cosurfactant mixture in the ratio of $1: 1$ and gently heated in a water bath to allow proper mixing. $25 \mu \mathrm{l}$ of this mixture was diluted to 25 $\mathrm{ml}$ with distilled water and the ease of formation of emulsions was monitored by the number of inversions required to produce a uniform emulsion. The emulsions were allowed to stand for $2 \mathrm{~h}$ and their transmittance was measured at $638.2 \mathrm{~nm}$ in UV-vis spectrophotometer against distilled water as the blank [20,24].

\section{Construction of a pseudo-ternary phase diagram}

A titration method was employed to construct phase diagrams. Various mixtures of the oil with surfactants or a combination of the surfactant and co-surfactant (Smix 2:1, 4:1, 6:1) was prepared at ratios of 10:0, 9:1, $8: 2,7: 3,6: 4,5: 5,4: 6,3: 7,2: 8,1: 9,0: 10$ into different vials. A small amount of water in $5 \%(\mathrm{w} / \mathrm{w})$ increments were added into the vials and shaken for $15 \mathrm{~min}$ to $30 \mathrm{~min}$ at $25^{\circ} \mathrm{C}$. Addition of water is done till the mixture is diluted to a maximum of to 1000 times. After each increment of water different phases were observed: (1) a clear liquid region that included clear or translucent solutions; (2) cloudy liquids apparently consisting of coarse emulsions; (3) a viscous gel; or (4) a phaseseparated mixture where the lipid separated from the aqueous phase to form a separate layer $[21,24]$.

\section{Preparation of SEDDS}

Based on the solubility studies and Phase diagram, the oil (gelucire 44/14), surfactant (labrasol) and co-surfactant (transcutol HP) were chosen for SEDDS formulations. A series of formulations were prepared using various concentrations $(10-80 \% \mathrm{v} / \mathrm{v})$ of oil, surfactant and co-surfactant. At first, the surfactant (labrasol) and co-surfactant (transcutol HP) were mixed in the ratio of $2: 1,4: 1$ and $6: 1$ and a specific quantity of $S_{\text {mix }}$ as shown in table 1 . The mixture obtained was mixed with gelucire 44/14 (oil) (which was previously heated at $45^{\circ} \mathrm{C}$ for $5 \mathrm{~min}$ in a water bath) until a clear solution was obtained. Then, an excess amount of etravirine was added to the mixtures and mixed thoroughly. The formulations were shaken at ambient temperature for $48 \mathrm{~h}$ and analyzed for etravirine content, as described above.

Table 1: SEDDS formulations with various percentage oil, surfactant and co-surfactant

\begin{tabular}{|c|c|c|c|c|c|}
\hline Formulation & 0: $S_{\text {mix }}$ & $\mathbf{S}_{\text {mix }}$ & Oil \% & Surfactant \% & Co-surfactant $\%$ \\
\hline F1 & $1: 9$ & $2: 1$ & 10 & 60 & 30 \\
\hline $\mathrm{F} 2$ & $2: 8$ & & 20 & 53.33 & 26.67 \\
\hline F3 & $3: 7$ & & 30 & 46.67 & 23.33 \\
\hline $\mathrm{F} 4$ & $4: 6$ & & 40 & 40 & 60 \\
\hline F5 & $5: 5$ & & 50 & 33.33 & 16.67 \\
\hline F6 & $6: 4$ & & 60 & 26.67 & 13.34 \\
\hline F7 & $7: 3$ & & 70 & 20 & 10 \\
\hline F8 & 1:9 & $4: 1$ & 10 & 72 & 18 \\
\hline F9 & $2: 8$ & & 20 & 64 & 16 \\
\hline F10 & $3: 7$ & & 30 & 56 & 14 \\
\hline F11 & $4: 6$ & & 40 & 48 & 12 \\
\hline F12 & $5: 5$ & & 50 & 40 & 10 \\
\hline F13 & $6: 4$ & & 60 & 32 & 8 \\
\hline F14 & $7: 3$ & & 70 & 24 & 6 \\
\hline F15 & $1: 9$ & $6: 1$ & 10 & 77.14 & 12.85 \\
\hline F16 & $2: 8$ & & 20 & 68.57 & 11.42 \\
\hline F17 & 3:7 & & 30 & 60 & 10 \\
\hline F18 & $4: 6$ & & 40 & 51.42 & 8.57 \\
\hline F19 & $5: 5$ & & 50 & 42.85 & 7.14 \\
\hline F20 & $6: 4$ & & 60 & 34.28 & 5.71 \\
\hline F21 & $7: 3$ & & 70 & 25.71 & 4.28 \\
\hline
\end{tabular}

\section{Evaluation of SEDDS}

\section{Percentage transmittance studies and self-emulsification} assessment

The self-emulsification of formulated SEDDS was evaluated using a standard USP XXII dissolution apparatus II. To carry out the study, a total of $0.1 \mathrm{ml}$ of the SNEDDS formulation was mixed with $100 \mathrm{ml}$ (1000 times dilution) of distilled water and gentle agitation was provided by rotating a standard stainless steel dissolution paddle at 50 RPM. Percentage transmittance was measured spectrophotometrically at $638.2 \mathrm{~nm}$ using water as a blank. The formulations were visually assessed for emulsification, precipitation and phase separation. $[20,22]$.

\section{Accelerated physical stability studies}

\section{Centrifugation study}

The formulations were diluted 100 times with distilled water, centrifuged at 3500-5000 RPM for $30 \mathrm{~min}$ and then examined visually for any phase separation. Then the formulations were visually observed for instability such as phase separation, creaming or cracking. The formulations that were free from phase separation, creaming and cracking were chosen for the heating-cooling cycle.

\section{Heating and cooling cycle}

This study so designed involved six cycles between $4{ }^{\circ} \mathrm{C}$ and $40{ }^{\circ} \mathrm{C}$ with storage at each temperature for not less than $48 \mathrm{~h}$. The formulations that did not show any sign of phase separation, creaming and cracking were considered as stable formulation.

Attenuated total reflection-fourier transform infrared spectroscopy (ATR-FTIR) analysis

To determine any interaction between the drug and any of the excipient used, ATR Spectra were recorded in the frequency range 4000-400 wave numbers (cm-1) using FTIR-8400S, Shimadzu.

\section{Globule size analysis}

The droplet size distribution and polydispersity index (PDI) of the optimized SEDDS formulation were determined by Zetasizer Nano ZS, Malvern Instruments, UK. The formulation $(0.1 \mathrm{ml})$ was added to 
$100 \mathrm{ml}$ of water in a volumetric flask and mixed by inverting the flask for 4-5 times. Then a few ml aliquot was withdrawn and added into a sample cell for droplet size measurement. Each size value reported was the average of three independent measurements.

\section{Transmission electron microscopy (TEM)}

The morphology of the optimized SEDDS formulation was investigated using transmission electron microscope (Tecnai G2 Spirit BioTwin) at an accelerated voltage of $120 \mathrm{KV}$. Briefly, a drop of diluted SNEDDS was placed on the grid. Approximately 2 min after sample deposition, the grid was tapped with filter paper to remove surface water and air-dried. The image was taken with transmission electron microscope at an acceleration voltage of $100 \mathrm{KV}[20,23]$.

\section{In vitro drug release}

The in vitro drug release of selected SEDDS formulation was performed in a USP XXIII apparatus I. Hard gelatin capsule containing the formulation was rotated at 50 RPM in the dissolution vessel containing $900 \mathrm{ml}$ of $0.01 \mathrm{M} \mathrm{HCl}$ with $1 \%$ SLS in double distilled water as dissolution media maintained at $37{ }^{\circ} \mathrm{C}$. A $1 \mathrm{ml}$ of the aliquots was withdrawn at predetermined time intervals, $(5,15$, 30,45 and $60 \mathrm{~min}$ ) from the dissolution medium and replaced with fresh blank media. The withdrawn samples were filtered using 0.45 mm Millipore filter and analyzed for drug content by UV-vis spectrophotometer (UV-1800, Shimadzu, Japan) using the corresponding blank medium at $317 \mathrm{~nm}[22,23,25]$.

\section{RESULTS AND DISCUSSION}

\section{Solubility study}

The SEDDS should have the good solvent capacity for the drug under investigation to achieve maximum drug loading in the final volume of SEDDS and should be a clear and monophasic liquid with good solvent capacity at ambient temperature when introduced to aqueous phase [26, 27]. The solubility of etravirine in various oils, surfactants and surfactants is shown in table 2. From the result, it is evident that etravirine exhibited the highest solubility in gelucire $44 / 14(110.3 \pm 10.01 \mathrm{mg} / \mathrm{ml})$ that was selected as an oil phase for further investigation. Gelucire $44 / 14$ is a medium chain lauroyl polyoxylglycerides official in european pharmacopoeia, which is a well-established excipient for solubility and bioavailability enhancement $[28,29]$. Surfactants tween $20(68.5 \mathrm{mg} / \mathrm{ml})$, tween 60 $(56.9 \mathrm{mg} / \mathrm{ml})$, tween $80(52.13 \mathrm{mg} / \mathrm{ml})$, cremophor EL $(38.63 \mathrm{mg} / \mathrm{ml})$ and cremophor RH60 $(70.92 \mathrm{mg} / \mathrm{ml})$ and co-surfactants PEG 200 $(59.98 \mathrm{mg} / \mathrm{ml})$, PEG $400(59.39 \pm 4.033)$ and transcutol HP (60.77 $\mathrm{mg} / \mathrm{ml}$ ) were selected for further studies since etravirine solubility was greater than $50 \mathrm{mg}$ except cremophor EL.

Table 2: Solubility of etravirine in vehicles

\begin{tabular}{ll}
\hline Oils/Vehicles & Solubility in mg/ml \\
\hline Gelucire 44/14 & $110.3 \pm 10.01$ \\
Captex 355 & $1.31 \pm 0.3748$ \\
Captex 300 & $1.57 \pm 0.2524$ \\
Tri Ester & $1.36 \pm 0.4356$ \\
Maisine 35-1 & $1.35 \pm 0.039$ \\
Lauroglycol 90 & $2.4 \pm 0.201$ \\
Labrafac & $1.73 \pm 0.1068$ \\
Tocopherol & $3.32 \pm 0.7495$ \\
Isopropyl Myristate & $0.64 \pm 0.0056$ \\
Oleic Acid & $3.63 \pm 1.039$ \\
Captex 200 & $4.44 \pm 0.1061$ \\
Castor Oil & $3.51 \pm 0.3111$ \\
Peceol & $5.87 \pm 1.980$ \\
Surfactants & \\
Tween 20 & $68.5 \pm 4.95$ \\
Tween 60 & $56.9 \pm 14.94$ \\
Tween 80 & $52.13 \pm 3.131$ \\
Span 80 & $7.86 \pm 7.741$ \\
Span 20 & $11.66 \pm 1.941$ \\
Labrafac WL 1349 & $1.73 \pm 0.1068$ \\
Caproyl PGMC & $13.81 \pm 0.0707$ \\
Labrasol & $73.11 \pm 9.525$ \\
Cremophor EL & $38.63 \pm 7.092$ \\
Cremophor RH 60 & $70.92 \pm 8.620$ \\
Co-surfactants & \\
PEG 200 & \\
PEG 400 & $59.98 \pm 2.503$ \\
Capmul MCM & $59.39 \pm 4.033$ \\
Transcutol HP & $7.22 \pm 0.9051$ \\
Capmul MCM C8 & $60.77 \pm 3.896$ \\
\hline
\end{tabular}

${ }^{a}$ Data expressed as mean $\pm S D(n=3)$

\section{Selection of surfactants}

Selection of surfactants in the formulation of SEDDS is crucial. The surfactants accepted for SEDDS should be safe, with relatively high hydrophilic-lipophilic balance (HLB) for the immediate formation of an emulsion or rapid spreading of the formulation and to solubilize high amount of lipophlic drug compounds. Generally, nonionic surfactants are preferred safer surfactants for oral ingestion since they impart stability to emulsion over a wider range of $\mathrm{pH}$ and ionic strength. Also, they facilitate absorption of the co-administered drug by making reversible changes in intestinal mucosal permeability [20, 17]. In our studies selection of surfactants was done based on their emulsifying ability which is determined by measuring the \% transmittance of the resulting emulsion [20]. All the selected surfactants showed good dispersing properties with greater transmittance value (table 3) which is attributed to higher HLB and hydrophilicity properties of surfactants [30].

\section{Selection of the co-surfactant}

Nonionic surfactant reduces interfacial tension, increases the flexibility of the interfacial film and helps in the spontaneous emulsion formation [31]. It is selected based on the number of inversions required to produce emulsion and \% transmittance of the dispersed emulsion. In comparison to PEG 200 and PEG 400 cosurfactants, transcutol showed transmittance greater than $90 \%$ with all the selected surfactants. The combination of oil with selected surfactant and co-surfactant are reported in table 3. 
Table 3: Emulsification efficiency with different surfactants and co-surfactants

\begin{tabular}{|c|c|c|c|c|c|c|c|c|c|}
\hline \multirow[t]{3}{*}{ Surfactant } & \multirow[t]{3}{*}{ HLB } & \multirow[t]{3}{*}{ In } & \multirow[t]{3}{*}{$\% \mathrm{~T}$} & \multicolumn{6}{|c|}{ Co-surfactant } \\
\hline & & & & \multicolumn{2}{|c|}{ Transcutol HP } & \multicolumn{2}{|c|}{ PEG 200} & \multicolumn{2}{|c|}{ PEG 400} \\
\hline & & & & In & \%T & In & \%T & In & \%T \\
\hline Tween 20 & 16.7 & 20 & 99.62 & 7 & 99.99 & 5 & 99.50 & 10 & 99.90 \\
\hline Tween 60 & 14.9 & 35 & 99.35 & 13 & 100 & 5 & 100.00 & 13 & 100.00 \\
\hline Tween 80 & 15 & 20 & 99.89 & 5 & 100 & 5 & 99.90 & 8 & 99.9 \\
\hline Cremophor EL & $12-14$ & 20 & 89.99 & 5 & 100 & 6 & 99.92 & 9 & 99.92 \\
\hline Cremophor RH60 & $15-17$ & 15 & 99.40 & 17 & 100 & 5 & 100.00 & 5 & 100.00 \\
\hline Labrasol & 14 & 10 & 71.55 & 8 & 99.6 & 5 & 81.72 & 5 & 84.64 \\
\hline
\end{tabular}

In: Number of Inversion, \%T: Percentage transmittance

\section{Construction of a pseudo-ternary phase diagram}

For a selection of surfactants forming wider emulsion region phase diagrams were constructed by the water titration method by mixing selected oil (gelucire 44/14) with different surfactants namely tween 20 , tween 60 , tween 80 , cremophor EL, cremophor RH 60 and labrasol. As depicted in (fig. 1) labrasol showed wider emulsifying area with selected oil gelucire 44/14. Nonionic surfactant labrasol a saturated polyglycolysed C6-C14 glyceride has a good solubilizing capacity of a hydrophobic drug, and ability to emulsify and enhance intestinal absorption of the drug [32-35]. Hence labrasol was selected as surfactant and transcutol was selected as co-surfactant since it is reported to be a solubilizer and absorption promoter [36, 37].

The ratio of surfactant to co-surfactant determines the emulsifying ability and plays an important role in the development of a stable emulsion by reducing interfacial energy and forming a barrier to coalescence [25]. Thus surfactant and co-surfactants were mixed in the ratio of 2:1, 4:1 and 6:1 for preparation of SEDDS.
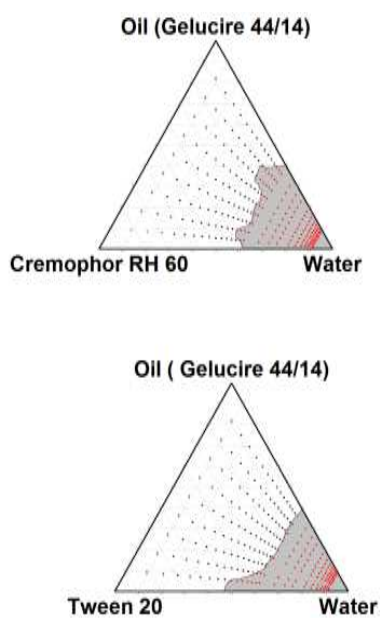
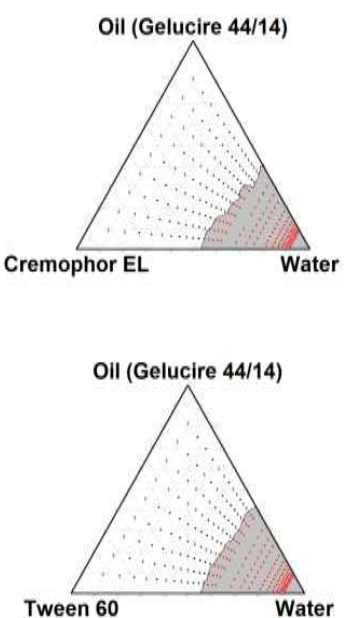
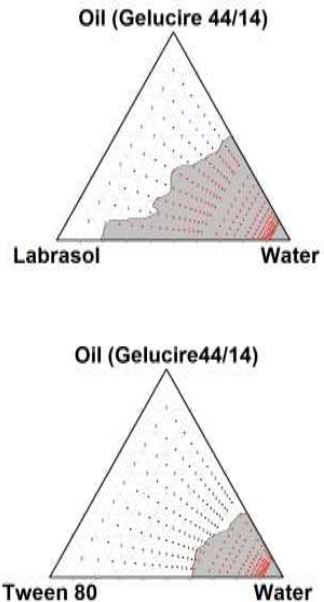

Fig. 1: Pseudo-ternary phase diagram of selected co-surfactant

Table 4: Characterization and stability testing of SEDDS formulations

\begin{tabular}{|c|c|c|c|c|c|}
\hline $\begin{array}{l}\text { Formulation } \\
\text { SEDDS with drug }\end{array}$ & $\%$ transmittance & $\begin{array}{l}\text { Stability after dilution } \\
\text { in Min }\end{array}$ & Stability after 1 mo & Centrifugation study & Heating and cooling cycle \\
\hline F1 & 41.2 & 20 & Clear Liquid & & \\
\hline $\mathrm{F} 2$ & 49.3 & 40 & Clear Liquid & stable & stable \\
\hline F3 & 52.6 & 35 & Clear Liquid & stable & stable \\
\hline F4 & 58.12 & 35 & Clear Liquid & stable & stable \\
\hline F5 & 60.35 & 40 & Translucent liquid & stable & stable \\
\hline F6 & 83.45 & 45 & Phase separation & -- & -- \\
\hline F7 & 84.5 & 20 & Phase separation & -- & - \\
\hline F8 & 54.7 & 30 & Clear Liquid & -- & -- \\
\hline F9 & 65.5 & 45 & Clear Liquid & stable & stable \\
\hline F10 & 70.3 & 35 & Phase separation & -- & -- \\
\hline F11 & 76.8 & 60 & Phase separation & -- & -- \\
\hline F12 & 84.51 & 50 & Phase separation & -- & -- \\
\hline F13 & 91.59 & 40 & Solidified & -- & -- \\
\hline F14 & 97.79 & 50 & Phase separation & -- & -- \\
\hline F15 & 40.5 & 40 & Clear liquid & -- & -- \\
\hline F16 & 60.1 & 40 & Clear liquid & stable & stable \\
\hline F17 & 63.45 & 40 & Phase separation & -- & -- \\
\hline F18 & 65.03 & 180 & Solidified & -- & -- \\
\hline F19 & 67.99 & 180 & Phase separation & -- & -- \\
\hline F20 & 77.32 & 40 & Phase separation & -- & -- \\
\hline F21 & 94.98 & 30 & Phase separation & -- & -- \\
\hline
\end{tabular}




\section{Preparation and characterization of SEDDS}

A sequence of SEDDS loaded with $50 \mathrm{mg}$ of drug were prepared using oil (gelucire 44/14) in the concentration range of $10 \%$ to $70 \%$ and mixed with $\mathrm{S}_{\text {mix }}$ (labrasol: transcutol mix). Visual assessment of SEEDS formulations was done after one month for clarity, precipitation and phase separation. SEDDS containing 10-40\% gelucire 44/14 was clear without precipitation and phase separation. SEDDS undergo gradual dilution in vivo to form an emulsion, so dilution test is done to find out phase separation and precipitation [38]. The SEDDS when diluted with water dispersed within $35 \mathrm{~s}$ to get non-turbid bluish white emulsion which indicated microemulsion formation [27] mainly due to higher HLB value of gelucire44/14 [33]. From dilution studies, it was observed that 6 formulations F2, F3, F4, F5, F9 and F16 were stable for $2-3 \mathrm{~h}$ without precipitation, but the rest of the formulation precipitated within 3060 min resulting in decreased \% transmittance. Results are depicted in table 4 . The stability of the 6 formulations was tested by the centrifugation test after forming microemulsion and observed immediately. There was no phase separation and precipitation, indicating the stability of the microemulsion formed [20].

\section{In vitro drug release}

The in vitro dissolution of etravirine from selected 6 SEDDS formulations was evaluated under sink conditions. Results are shown in the fig. 2. Pure drug showed $20 \%$ drug release in $2 \mathrm{hr}$ and all other 6 formulations released more than $80 \%$ of the drug in first $5 \mathrm{~min}$ and decreased to $25 \%$ (F2), 32\% (F3), 27\% (F4), 30\% (F5), $39 \%$ (F9) and $41 \%$ (F16) at $2 \mathrm{hr}$. the decrease in the percentage release can be ascribed to, precipitation of the drug form SEDDS. For the correlation between dissolution and time, $\mathrm{DT}_{50}$ was calculated, which is the time required to maintain the dissolution rate over $50 \%$ [39]. Formulation F16 showed maximum $\mathrm{DT}_{50}$ of 79 min compared to all other formulations and pure drug. Hence F16 was selected as optimum SEDDS formulation with $20 \%$ oil, $68.57 \%$ surfactant and $11.42 \%$ co-surfactant.

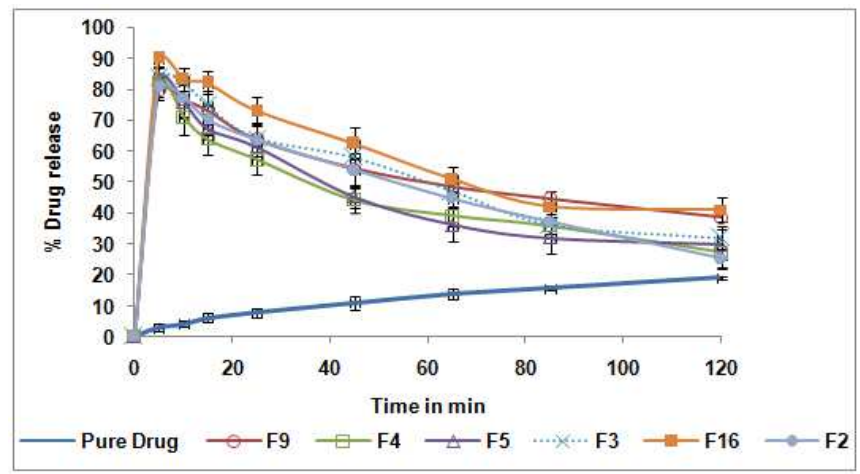

Fig. 2: In vitro dissolution of selected SEDDS formulations

\section{Characterization of optimized formulation}

Optimized formulation F16 was analyzed for compatibility of the drug with excipients by ATR-FTIR. Spectra of drug confirms the presence of aromatic amine and amide stretching peak at $3300 \mathrm{~cm}^{1}$ and $3500 \mathrm{~cm}^{1}$ and aromatic aryl stretching between $2220-2260 \mathrm{~cm}^{1}$. Blank SEDDS without drug showed main $\mathrm{OH}$ stretching at $3470 \mathrm{~cm}^{1}$, CH3 stretching peak at $2868 \mathrm{~cm}^{1}$ and $\mathrm{C}=0$ stretching at $1735 \mathrm{~cm}^{-1}$ respectively which is due to triglycerides. Optimized SEDDS formulation F16 after one month showed overlapping of NH group of the drug with $\mathrm{OH}$ group of SEDDS vehicles and other peaks remained unchanged (fig. 3). Similar peaks were observed after 6 mo indicating stability of the formulation.
Transmission electron microscopic analysis was performed to investigate the morphology of the microemulsion after dilution. The droplet size analysis showed the quality of emulsion formed. The decrease in the droplet size reflects the formation of a better, close-packed film of the surfactant at the oil-water interface, thereby stabilizing the oil droplets [40]. The droplets size of F16 emulsion was found to be within $200 \mathrm{~nm}$ with zeta potential of $\pm 36.8 \mathrm{mV}$, which indicates the submicron range with good stability after dilution [41]. Globule size and PDI of F16 formulation were found to be $159 \mathrm{~nm} \pm 0.156$ and PDI of $0.103 \pm 0.012$, (fig. 4 and 5) which is a good indication of microemulsion formation with good PDI.

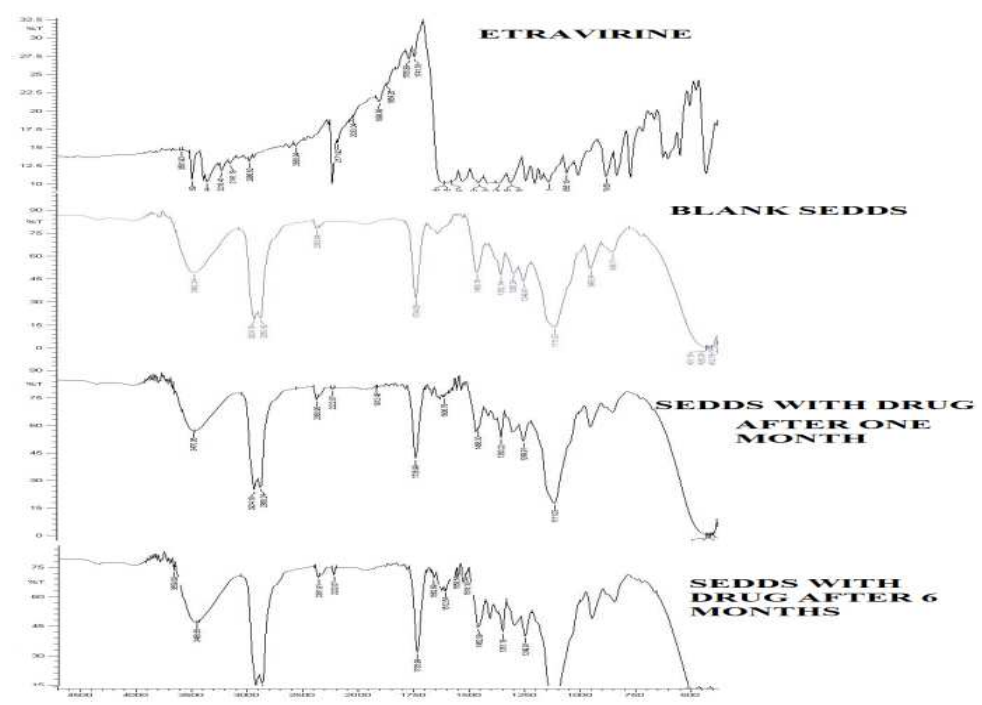

Fig. 3: FTIR of drug and SEDDS formulation 


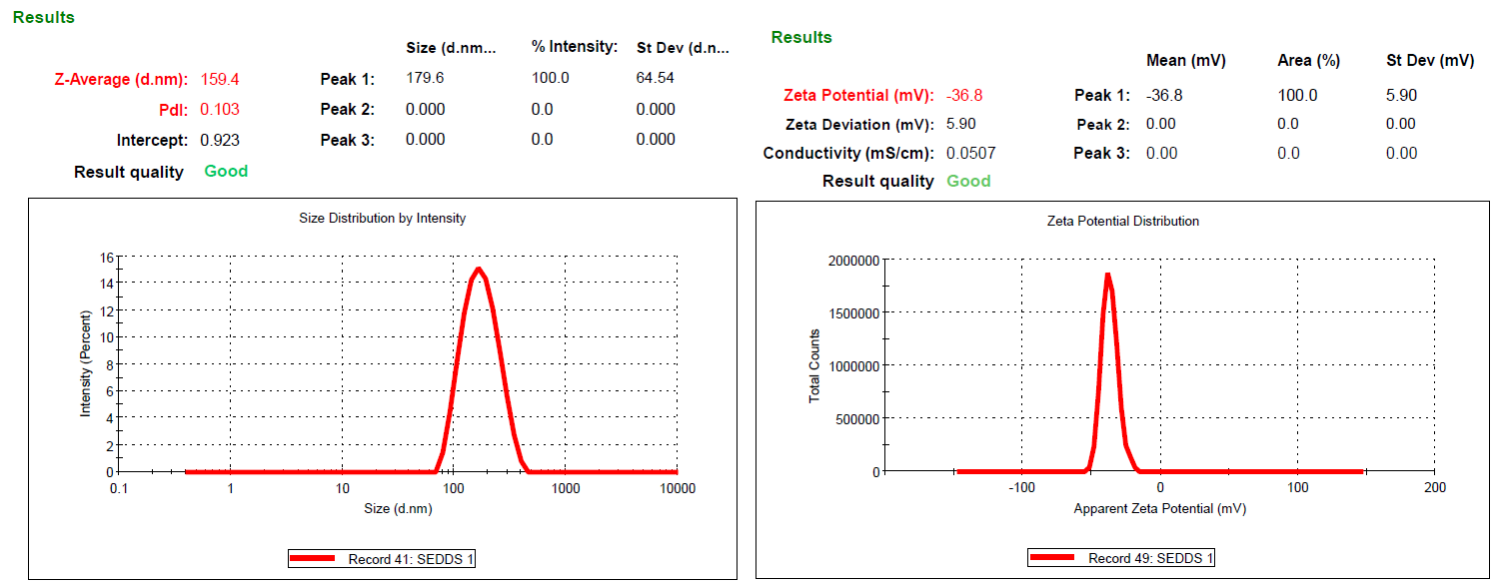

Fig. 4: Average size, PDI and zeta potential of SEDDS formulation F16

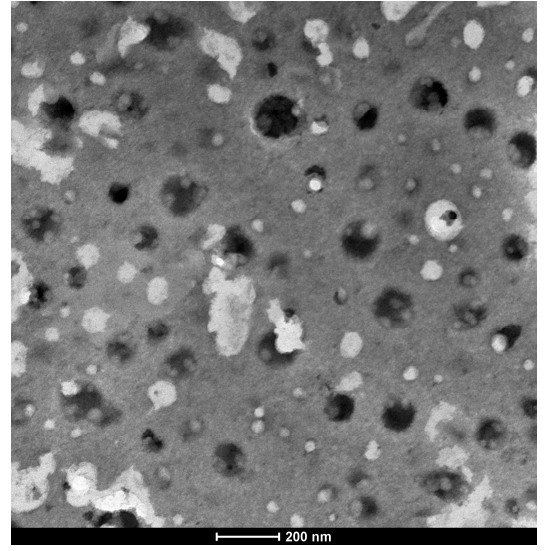

Fig. 5: TEM image of SEDDS formulation F16

\section{CONCLUSION}

Prototype SEDDS of etravirine was successfully formulated and investigated for its potential use for improving in vitro dissolution. Several SEDDS were prepared and evaluated for emulsification property and stability. The optimized SEDDS of etravirine showed enhanced dissolution rate compared to that of the pure drug with desired property of SEDDS. The added components in SEDDS, gelucire 44/14, labrasol and transcutol enhanced solubility and likely to enhance bioavailability by transporting the drug by transcellular route. Therefore SEDDS can be a viable formulation strategy for the oral delivery of etravirine. Further investigations are essential for confirming the potentiality of the etravirine selfemulsifying system.

\section{ACKNOWLEDGEMENT}

Nil

\section{AUTHORS CONTRIBUTIONS}

All the author have contributed equally

\section{CONFLICT OF INTERESTS}

\section{Declared none}

\section{REFERENCES}

1. Elizabeth O, Irene M, Panjasaram N, Thirumala G. Exploring the use of novel drug delivery systems for antiretroviral drugs. Eur J Pharm Biopharm 2008;70:697-710.

2. Archita P, Anita L. Self micro emulsifying drug delivery system as a potential drug delivery system for protease inhibitors in the treatment of AIDS. Asian J Pharm 2011;6:226-40.
3. Umesh G, Narendra KJ. Non-polymeric nano-carriers in HIV/AIDS drug delivery and targeting. Adv Drug Delivery Rev 2010;62:478-90.

4. Marie PB. Non-nucleoside reverse transcriptase inhibitors (NNRTIs), their discovery, development, and use in the treatment of HIV-1 infection: a review of the last 20 y (19892009). Antiviral Res 2010;85:75-90.

5. Schiller DS, Youssef-Bessler M. Etravirine: a second-generation non-nucleoside reverse transcriptase inhibitor (NNRTI) active against NNRTI-resistant strains of HIV. Clin Ther 2009;31:692-704.

6. Jessica A, Nimish P, Nancy, Mariam T, Christopher DM. Nonnucleoside reverse transcriptase inhibitor resistance and the role of the second-generation agents. Ann Pharmacother 2010;44:157-65.

7. Leonard B Johnson, Louis D Saravolatz. Etravirine, a nextgeneration non-nucleoside reverse-transcriptase inhibitor. Clin Infect Dis 2009;48:1123-8.

8. Yohei K, Koichi W, Manabu N, Shizuo Y, Satomi O. Formulation design for poorly water-soluble drugs based on biopharmaceutics classification system: basic approaches and practical applications. Int J Pharm 2011;420:1-10.

9. Sandeep K, Mohanvarma M, Veerabhadhraswamy P. Oral lipidbased drug delivery systems-an overview. Acta Pharm Sinica B 2013;3:361-72.

10. Colin W Pouton. Lipid formulations for oral administration of drugs: non-emulsifying, self-emulsifying and 'self-micro emulsifying' drug delivery systems. Eur J Pharm Sci 2000;11 Suppl 2:S93-8.

11. Christopher JH Porter, Colin WP, Jean F Cuine, William NC. Enhancing intestinal drug solubilisation using lipid-based delivery systems. Adv Drug Delivery Rev 2008;60:673-91.

12. Jaime AY, Stephen WJ Wang, Ian WK, Mark AW, Kevin BA. Intestinal lymphatic transport for drug delivery. Adv Drug Delivery Rev 201;163:923-42.

13. Anne C, Thomas B, Werner W. Effects of non-ionic surfactants on in vitro triglyceride digestion and their susceptibility to digestion by pancreatic enzymes. Eur J Pharm Sci 2010;41:376-82.

14. Gershanik T, Benita S. Self-dispersing lipid formulations for improving oral absorption of lipophilic drugs. Eur J Pharm Biopharm 2000;50:179-88.

15. Mohd JQ, Chitneni M, Wong GK. Enhancement of solubility and therapeutic potential of poorly soluble lovastatin by SMEDDS formulation adsorbed on directly compressed spray dried magnesium aluminometasilicate liquid loadable tablets: a study in diet-induced hyperlipidemic rabbits. Asian J Pharm 2015;10:40-56.

16. Naser MY Hasan. Role of medium-chain fatty acids in the emulsification mechanistics of self-micro-emulsifying lipid formulations. Saudi Pharm J 2014;22:580-90.

17. R Neslihan Gursoy, Simon B. Self-emulsifying drug delivery systems (SEDDS) for improved oral delivery of lipophilic drugs. Biomed Pharmacother 2004;58:173-82. 
18. Zupancic O, Grießinger JA, Rohrer J, Pereira de Sousa I, Danninger L, Partenhauser A, et al. Development in vitro and in vivo evaluation of a self-emulsifying drug delivery system (SEDDS) for oral enoxaparin administration. Eur J Pharm Biopharm 2016;109:113-21.

19. Huiyi W, Xiaoying L, FeiYuana, Li C, Sujing P, Yunjun L, et al. Combined use of phospholipid complexes and self-emulsifying microemulsions for improving the oral absorption of a BCS class IV compound, baicalin. Acta Pharm Sin B 2014;4:217-26.

20. Shweta G, Sandip C, Krutika KS. Self-nanoemulsifying drug delivery system for adefovir dipivoxil: design, characterization, in vitro and ex vivo evaluation. Colloids Surf A 2011;392:145-55.

21. Prajapati HN, Dalrymple DM, Serajuddin AT. A comparative evaluation of mono-, di-and triglyceride of medium chain fatty acids by lipid/surfactant/water phase diagram, solubility determination and dispersion testing for application in pharmaceutical dosage form development. Pharm Res 2012;29:285-305

22. Prakash CS, Sunit KS, Alakh NS. Mixed surfactant based (SNEDDS) self-nanoemulsifying drug delivery system presenting efavirenz for enhancement of oral bioavailability. Biomed Pharmacother 2016;80:42-51.

23. Kotta S, Khan AW, Ansari SH, Sharma RK, Ali J. Anti HIV nanoemulsion formulation: Optimization and in vitro-in vivo evaluation. Int J Pharm 2014;462:129-34.

24. Shubham R, Mohd Y. Cinnarizine loaded lipid-based system: preparation, optimization and in-vitro evaluation. J Pharm 2012;2:47-56.

25. Meena AK, Sharma K, Kandaswamy M, Rajagopal S, Mullangi R. Formulation development of an albendazole self-emulsifying drug delivery system (SEDDS) with enhanced systemic exposure. Acta Pharm 2012;62:563-80.

26. Amit AK, Vandana BP. Design and evaluation of self-emulsifying drug delivery systems (SEDDS) of nimodipine. AAPS PharmSciTech 2008;9:191-6.

27. Patel D, Sawant KK. Oral bioavailability enhancement of acyclovir by self-micro emulsifying drug delivery systems (SMEDDS). Drug Dev Ind Pharm 200;33:1318-26.

28. Soliman MS, Khan MA. Preparation and in vitro characterization of a semi-solid dispersion of flurbiprofen with Gelucire 44/14 and Labrasol. Pharmazie 2005;60:288-93.

29. Jannin V, Musakhanian J, Marchaud D. Approaches for the development of solid and semi-solid lipid-based formulations. Adv Drug Delivery Rev 2008;60:734-46.
30. Gershanik T, Benita S. Self-dispersing lipid formulations for improving oral absorption of lipophilic drugs. Eur J Pharm Biopharm 2000;50:179-88.

31. Syed HK, Peh KK. Identification of phases of various oil, surfactant/co-surfactants and water system by ternary phase diagram. Acta Pol Pharm 2014;71:301-9.

32. Venkata RK, Basanth BE, Raju J, Ram KA, Suresh B. A gelucire 44/14 and labrasol based solid self-emulsifying drug delivery system: formulation and evaluation. J Pharm Investig 2013; 43:185-96.

33. Yüksel N, Karataș A, Ozkan Y, Savașer A, Ozkan SA, Baykara T. Enhanced bioavailability of piroxicam using Gelucire $44 / 14$ and labrasol: in vitro and in vivo evaluation. Eur J Pharm Biopharm 2003;56:453-9.

34. Koga K, Kusawake Y, Ito Y, Sugioka N, Shibata N, Takada K. Enhancing mechanism of Labrasol on intestinal membrane permeability of the hydrophilic drug gentamicin sulfate. Eur J Pharm Biopharm 2006;64:82-91.

35. Prasad YV, Puthli SP, Eaimtrakarn S, Ishida M, Yoshikawa Y, Shibata N, et al. Enhanced intestinal absorption of vancomycin with Labrasol and D-a-tocopheryl PEG 1000 succinate in rats. Int J Pharm 2003;250:181-90.

36. Delongeas JL, de Conchard GV, Beamonte A, Bertheux H, Spire C, Maisonneuve C, et al. Assessment of Labrasol_/ labrafil_/Transcutol_ $(4 / 4 / 2, \mathrm{v} / \mathrm{v} / \mathrm{v})$ as a non-clinical vehicle for poorly water-soluble compounds after 4-week oral toxicity study in wistar rats. Regul Toxicol Pharmacol 2010;57:284-90.

37. Mura P, Faucci MT, Bramanti G, Corti P. Evaluation of transcutol as a clonazepam transdermal permeation enhancer from hydrophilic gel formulations. Eur J Pharm Sci 2000;9:36572.

38. Mahmoud DB, Shukr MH, Bendas ER. In vitro and in vivo evaluation of self-nano emulsifying drug delivery systems of cilostazol for oral and parenteral administration. Int J Pharm 2014;476:60-9.

39. Lee DH, Yeom DW, Song YS, Cho HR, Choi YS, et al. Improved oral absorption of dutasteride via Soluplus1-based supersaturable self-emulsifying drug delivery system (SSEDDS). Int J Pharm 2015;478:341-7.

40. Nahla SB. Enhanced oral bioavailability of etodolac by selfemulsifying systems: in vitro and in vivo evaluation. J Pharm Pharmacol 2010;62:173-80.

41. Jaydeep P, Anjali P, Mihir R, Navin S. Formulation and development of a self-nanoemulsifying drug delivery system of irbesartan. J Adv Pharm Technol Res 2011;2:9-16. 